\title{
AVALIAÇÃO DO REPLANTIO DA VEGETAÇÃO DO MANGUEZAL NO SACO DA FAZENDA, ITAJAÍ(SC)
}

\author{
TOGNELLA-DE-ROSA, M.M.P.1; LUGLI, D.O.; OLIVEIRA, R.G.; SCHALLENBERG, B.H. ${ }^{4}$ \& \\ J.F. WILLRICH
}

\author{
Laboratório de Ecologia da Vegetação Costeira - CTTMar/Univali \\ 1'monica.tognella@univali.br, ${ }^{2} I u g l i @ u n i v a l i . b r, 3$ rafaela_go@univali.br, \\ 4bahecks@yahoo.com.br
}

\begin{abstract}
RESUMO
O presente estudo compreende as atividades de marcação e monitoramento do processo de replantio da vegetação do manguezal que coloniza a orla do Saco da Fazenda, Itajaí (SC), correspondendo às etapas desenvolvidas no período de março a dezembro de 2001. A metodologia consistiu na marcação das árvores e na observação do diâmetro basal e altura de cada indivíduo, bem como no estado geral do caule, folhas e raízes. Nesse período de estudo foram etiquetados 350 indivíduos. As alturas máximas observadas raramente ultrapassam 3,5 m e os maiores diâmetros encontram-se na faixa de 4,0 a $4,5 \mathrm{~cm}$. O maior índice de mortos ocorreu no intervalo de altura superior a $1,0 \mathrm{~m}$ e com diâmetros entre 1,0 a 2,0 cm. Indivíduos com altura superior a 3,0 m apresentaram $100 \%$ de mortalidade. Indivíduos com maior altura que permaneceram vivos, encontrava-se nas porções mais internas do bosque transplantado, pois nessa área é menor o estresse mecânico provocado pela inundação de maré.
\end{abstract}

Palavras-chave: replantio, jovens, monitoramento, Laguncularia racemosa.

MANGROVE REPLENISHEMENT AVALIATION IN SACO DA FAZENDA, ITAJAÍ (SC)

\begin{abstract}
In this work the survival and performance of transplanted mangrove trees in Saco da Fazenda (Itajaí, SC), were monitored from March to December 2001. Three hundred and fifty transplanted trees were tagged and the trunk basal diameter and tree height were measured. The health of trunk, leaves and roots were also observed. Maximum tree heights were about $3.5 \mathrm{~m}$ and larger trunk diameters were about $4.0-4.5 \mathrm{~cm}$. Mortality was higher to trees higher than $1.0 \mathrm{~m}$. Trees higher than $3.0 \mathrm{~m}$ did not survive to replenishment. Survival of high trees occurred only in areas protected from hydrodynamics, were stress by sand mobility were lower.
\end{abstract}

Keys words: replenishment, mortality, Laguncularia racemosa.

\section{INTRODUÇÃO}

Após a conclusão da etapa de replantio da vegetação de mangue no Saco da Fazenda (Itajaí, SC), cujos procedimentos encontram- se descritos em Tognella-De-Rosa (2002). Subseqüente ao replantio, levantamentos de campo foram realizados com intuito de monitorar a vegetação e estimar quais fatores ambientais que estariam influenciando na recuperação do manguezal. 
A espécie Laguncularia racemosa é um vegetal com bastante plasticidade em relação aos impactos ambientais induzidos pelo homem e aos naturais, tendo sido observada com freqüência sua ocorrência como sucessora secundária em locais impactados (Peria et al., 1990). Devido a estas características esta espécie é adequada para a recuperação de manguezais, favorecendo a manutenção da flora do Saco da Fazenda.

O replantio foi realizado em área contígua ao bosque de mangue original procurando preservar ao máximo os indivíduos durante o processo de transplante.

\section{MATERIAIS E MÉTODOS}

Durante o período de março a dezembro de 2001, foram realizadas saídas semanais para observação visual do manguezal replantado e saídas mensais para o monitoramento dos indivíduos marcados, correspondendo à marcação de $1 / 3$ dos indivíduos replantados.

O processo de demarcação foi bastante lento devido às condições do local, o sedimento é bastante fluido e a área frontal bastante inundada. Esses aspectos restringiam a amostragem a um período de tempo bastante curto durante a maré baixa.

A metodologia desenvolvida nessa etapa do estudo de recuperação da vegetação de mangue consiste na marcação das árvores replantadas e na observação do diâmetro e altura de cada indivíduo, bem como o estado geral do caule, folhas e raízes (exposta ou não).

Tendo em vista a estatura dos indivíduos transplantados, a metodologia proposta por Cintron \& Schaeffer-Novelli (1983) foi modificada para o presente estudo. Uma porcentagem relativamente alta dos indivíduos replantados apresentava estatura inferior a 2,00 metros, tendo seu diâmetro a 1,30 metro pequena dimensão, consequentemente, leituras realizadas conforme a metodologia padrão implicaria num aumento do erro amostral. Desta forma, determinou-se que a leitura desse parâmetro fosse realizada na base do caule para todos os indivíduos indistintamente de sua altura total. Com essa estimativa, os indivíduos marcados poderão ser observados por vários anos, identificando se houve ou não incremento em biomassa e qual a taxa deste parâmetro.

Tanto a altura quanto o diâmetro foram determinados empregando-se trena métrica e trena calibrada em $\pi$, respectivamente. Além dessas observações cada indivíduo é etiquetado com marca numerada, possibilitando o monitoramento em longo prazo destes parâmetros para os mesmos indivíduos.

As árvores foram etiquetadas e classificadas dentro de três categorias: vivas, mortas e semimortas. Esta última categoria designa árvores que apresentam todas as suas folhas eliminadas ou um número muito pequeno delas. Entretanto, os caules e galhos apresentavam-se em boas condições ou havia indicações de brotamento das folhas, fatores que podem contribuir para a sobrevivência do indivíduo.

Durante as observações de campo, cada indivíduo teve a sua posição definida em relação ao fluxo de maré (grande, média e pequena influência de inundação e stress mecânico) para aferir se havia relação entre esse parâmetro abiótico na taxa de sobrevivência das árvores.

Em laboratório, esses dados foram colocados em planilhas eletrônicas para análise e interpretação. Os dados analisados forneceram os índices de mortalidade, sobrevivência, recuperação ou morte de indivíduos, por classe de diâmetro e de altura, por localização ao longo do estudo de monitoramento.

\section{RESULTADOS E DISCUSSÃO}

Nessa etapa inicial foram etiquetados 350 indivíduos sendo que alguns deles contêm mais de um tronco, o que totalizou 366 amos- 
tras ou troncos. Os demais indivíduos foram demarcados após esse período.

A avaliação da localização de cada indivíduo replantado foi importante porque com essa observação pode-se constatar que os indivíduos em áreas com maior influência de maré apresentam uma taxa de mortalidade mais alta. Obviamente, a incidência de ondas e fluxo de maré torna-se fonte subsidiária de estresse que contribui para alocar energia do indivíduo, dificultando seu restabelecimento.

Os resultados obtidos até o momento, representando a terça parte da vegetação replantada, descrevem uma taxa de mortalidade de $42 \%$. Comparando com outros estudos de replantio, essa taxa observada foi bastante baixa. Em outros locais, muitas vezes a taxa de mortalidade alcança índices de $100 \%$, quando realizada com indivíduos maiores que um metro de altura (Saenger, 1996).

Considerando o número de indivíduos mortos com taxa de mortalidade atual estimada em $42 \%$, a classificação apresentada de pequena, média e grande influência do fluxo de ondas e marés permitiu avaliar que $75 \%$ dos indivíduos mortos encontravam-se na área de grande influência da maré e ondas.

A figura 1 descreve distribuição dos indivíduos transplantados por classe de diâmetro,

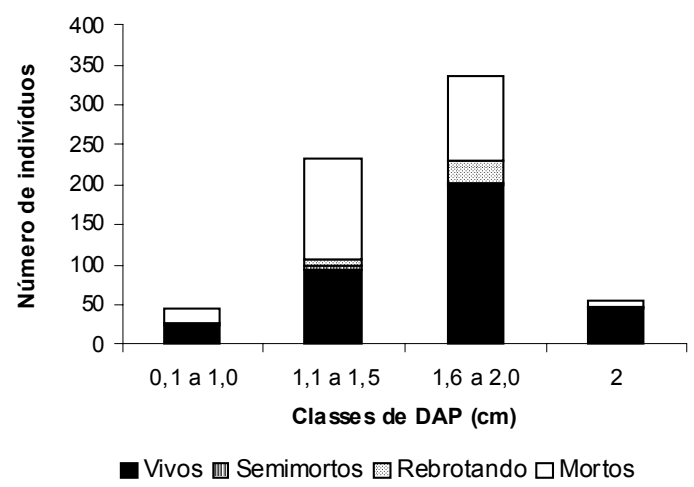

Figura 1 - Indivíduos transplantados classificados em vivos, semimortos, rebrotando e mortos por classe de diâmetro. tendo sido selecionado 4 classes de diâmetro. Pode-se observar que o número de indivíduos contendo diâmetro superior a $2,0 \mathrm{~cm}$ é baixo, tanto para indivíduos vivos quanto mortos, sendo que os maiores diâmetros observados encontram-se na faixa de 4,0 a $4,5 \mathrm{~cm}$, fato que se mantém similar até o momento para os demais indivíduos amostrados. Isso demonstra que os indivíduos transplantados fazem parte de uma mesma coorte de ingresso no bosque original, caracterizando aspecto de colonização dos manguezais (Cintron \& SchaefferNovelli, 1983). As maiores densidades ocorrem na classe definida entre 1,6 a $2,0 \mathrm{~cm}$. A classe de diâmetro que apresentou maior mortalidade foi àquela definida entre $1,1 \mathrm{a} 1,5 \mathrm{~cm}$, provavelmente devido menor sustentabilidade dos indivíduos em relação à altura.

A figura 2 corresponde à análise realizada para as diferentes classes de altura. Proporcionalmente, a classe de altura situada entre 1,0 a $1,5 \mathrm{~m}$ foi a que apresentou maior número de mortos. A densidade de árvores cuja estatura é superior a 2,0 $\mathrm{m}$ foi bastante pequena, tendo sua mortalidade minimizada buscando replantar estes indivíduos de forma mais protegida.

O parâmetro biológico mais significante para análise, dentre esses dois observados, é

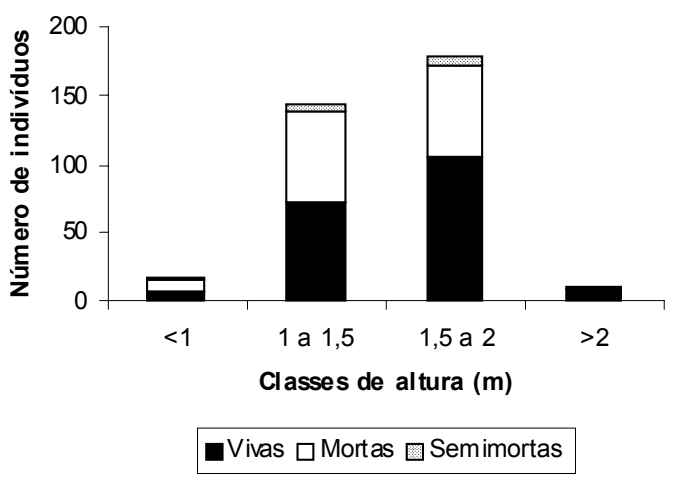

Figura 2 - Indivíduos transplantados classificados em vivos, semimortos, rebrotando e mortos por altura. 
a altura que resulta num comprometimento maior da vegetação em situações de estresse.

Em diversas situações de alteração ambiental já foram observados que os galhos e folhas mais altas são os primeiros a perecer. Isso está relacionado à dificuldade encontrada pelos indivíduos em adquirir água e sais minerais do solo e transportá-los até as porções mais altas. Devido ao estresse, essas porções do vegetal são as mais comprometidas porque a coluna de seiva bruta a ser deslocada é maior, tornando a elevação de sais e nutrientes mais dispendiosa.

Outro fator que pode estar influenciando na mortalidade relacionada à altura do indivíduo é a extensão do sistema de raízes. Quanto maior o indivíduo e sua copa, maior a profundidade e/ou extensão lateral das raízes. Consequentemente, mesmo com os cuidados desprendidos durante a retirada e replantio dos indivíduos houve maior impacto sobre o sistema de raízes de árvores maiores. Alterações na interação raiz/sedimento comprometem a assimilação de nutrientes pelo vegetal.

Analisando o conjunto de indivíduos mortos em relação ao parâmetro altura, constata-se que o maior índice de mortos ocorreu no intervalo de altura superior a 1,00 metro. Os poucos indivíduos transplantados com altura superior a 3,00 metros tiveram $100 \%$ de mortalidade, representados em baixa densidade na figura 2. Esses indivíduos apresentavam um conjunto de variáveis como maior altura, diâmetro grande e menor influência de ondas e marés, fatores estes que comprometeram a sobrevivência dos indivíduos nessa classe de altura.

No intervalo de estatura entre 2,00 e 2,99 metros só sobreviveram os indivíduos com um número de folhas superior a 50 , sendo que a maioria deles localizava-se na área de pequena influência de maré e ondas.

Em relação aos indivíduos vivos, aqueles que apresentaram estatura superior a 2,0 m e sobreviveram, encontravam-se nas porções mais internas do bosque transplantado. Em geral, essa categoria de sobrevivente, além da proteção, apresenta um número maior de foIhas por caule.

Quanto mais internamente localizava-se o indivíduo, menor era o estresse mecânico provocado pelas oscilações de maré e pela freqüência de inundação. Esse fator provoca modificações no substrato, em alguns casos, resultando em exposição do sistema de raízes. Além disso, há o comprometimento do equilíbrio dos indivíduos de maior porte, dificultando a produção de raízes para a fixação do indivíduo e sua própria nutrição.

A tabela 1 apresenta o número total de indivíduos dentro da classificação fisiológica de mortos, semimortos e vivos. Utilizando essas mesmas informações associadas à posição dos mesmos no campo, a saber: grande, média e pequena influência de ondas e marés - determinou-se também a proporção de indivíduos mortos, semimortos e vivos por área, como demonstrado na tabela.

Esses dados permitem identificar que a oscilação da maré e sua energia de onda fo-

Tabela 1 - Proporção de indivíduos classificados como mortos, semimortos e vivos relacionados com o total de indivíduos e com o número de indivíduos por área de distribuição.

\begin{tabular}{cccc}
\hline Posição & Mortos & Semimortos & Vivos \\
\hline Grande & $75 \%$ & $50 \%$ & $42 \%$ \\
Média & $13 \%$ & $25 \%$ & $8 \%$ \\
Pequena & $12 \%$ & $25 \%$ & $50 \%$ \\
\hline Total & $\mathbf{4 2} \%$ & $\mathbf{3} \%$ & $\mathbf{5 5 \%}$ \\
\hline
\end{tabular}


ram fatores que mais contribuíram para a taxa de mortalidade. Isso permite recomendar que em processos de replantio seja realizada uma proteção dos indivíduos contra o choque mecânico provocado por marés e ondas. Quando os indivíduos apresentavam altura elevada esse estresse foi mais acentuado.

Um outro aspecto que cabe discutir para analisar o número de indivíduos mortos é o aporte de materiais alóctones, principalmente troncos e madeiras grandes, que chegam à área transportados pela maré. Muitos dos mortos foram derrubados por esses troncos, o que se torna essa outra fonte de mortalidade bastante representativa. Os troncos, mesmo pequenos, interferem no estabelecimento da vegetação ou, então, no soterramento dos indivíduos. Por diversas ocasiões, árvores vivas foram retiradas debaixo de troncos ou levantadas para mantêlas vivas. Algumas que tiveram suas raízes expostas por ação do impacto de objetos ou por ação das ondas e marés foram recobertas novamente durante as atividades em campo de monitoramento semanal, procurando amenizar o impacto e diminuir a taxa de mortalidade.

\section{CONSIDERAÇÕES FINAIS}

Até o momento, pode-se obter as seguintes considerações sobre a questão de replantio de manguezal:

Durante a retirada das plantas deve haver o maior cuidado possível com o sistema de raízes.

As plantas devem ser imediatamente replantadas para não ressecar as raízes.

Não se recomenda o replantio de indivíduos maiores que 2,0 metros de altura devido ao grande insucesso na operação.

Manter as mesmas condições abióticas do local anterior (nível de maré, regime de ondas, salinidade, temperatura entre outros).

Alterar o mínimo possível o substrato para replantio.

Montar estruturas que amenizem a energia de ondas que incide sobre os indivíduos replantados.

Não se recomenda alteração no ecossistema por ocasião do inverno.

O custo do empreendimento é bastante alto, tornando-se totalmente inviável para áreas muito grande.

\section{REFERÊNCIAS BIBLIOGRÁFICAS}

Cintrón, G. \& Y. Schaeffer-Novelli. 1983. Introduccion a la ecologia del manglar. UNESCO/ROSTLAC.

Peria, L.C. S.; Fernandes, P.P.C.P.; Menezes, G.V.; Grasso, M. \& M.M.P. Tognella. 1990. Estudos estruturais comparativos entre bosques de mangue impactados (Canal da Bertioga) e não impactados (llha do Cardoso), Estado de São Paulo. Publicação ACIESP, 71(2): 183-193.

Saenger, P. 1996. Restauracion de Manglares em Columbia: Estúdio de caso Del Parque Nacional Natural, p. 209-217 In: C. Field [Ed.], La restauracion de ecosistema del manglar. Sociedade Internacional para Ecosistemas de Manglar. ISME.

Tognella-De-Rosa, M.M.P.; Oliveira, R.G.; Lugli, D.O.; Willrich, J.F.; Meireles, R.P. \& T.V. Poletto. 2002. Replantio da Vegetação do Manguezal do Saco da Fazenda, Itajaí (SC). Notas Téc. FACIMAR, 6:85-91. 